\title{
Knowledge Creation and Flow in Agriculture: the Experience and Role of the Japanese Extension Advisors
}

\author{
Sohaimi Zakaria ${ }^{1}$ and Haruki Nagata ${ }^{2}$
}

${ }^{1}$ Associate Professor, Faculty of Information Management, Universiti Teknologi MARA, Malaysia. Foreign Visiting Research Fellow, Research Center for Knowledge Communities, Graduate School of Library, Information \& Media Studies, University of Tsukuba, Japan. Email: sohaimiz@salam.uitm.edu.my

${ }^{2}$ Professor, Research Center for Knowledge Communities, Graduate School of Library, Information \& Media Studies, University of Tsukuba, Japan.

Email: harungt@slis.tsukuba.ac.jp

\begin{abstract}
This paper presents findings of a recent study on the experience and roles of agricultural extension advisors in the context of knowledge creation and flow in organizations. Data were collected through interviews with eleven principal and senior extension advisors and a consultant from different Prefectures and organizations as well as questionnaires from 135 extension advisors in the Ibaraki Prefecture, Japan. The purpose of the study was to explore the preferences and roles played by extension advisors in relation to knowledge sharing among advisors, farmers and other stakeholders. Results show that the Japanese agricultural agencies are actively involved in facilitating knowledge creation within their organizations. The extension advisors, as intermediaries and catalysts, are the key links between farmers and the relevant agencies in terms of providing personalized and need-based information for decision-making.
\end{abstract}

Keywords: knowledge creation, knowledge sharing, information use, knowledge flow, agricultural information, agricultural extension, information management, agriculture, information intermediary

\section{Introduction}

The Japanese agriculture has experienced several phases of reforms and modernization for more than a century ago. Since the end of the Second World War Japan started to embark on a concerted effort to revitalize its agriculture sector in order to boost production to meet the escalating demand for food. The Central and Prefectural Governments worked closely to enhance the training of farmers to uplift their technical and managerial skills and to ensure sustainability, and this was remarkably carried out through the activities and programs by the agricultural extension services.

The Japanese extension system for agriculture which started in 1948 was meant for helping farmers to acquire useful, appropriate and practical knowledge in the domain of agriculture (Fujita, n. d.). This system was adapted from the Western extension system into the Japanese culture to suit their local needs and requirements. Traditionally, extension focuses on disseminating R\&D information from research laboratories to farmers (Roling, 1990), providing farmers with technical advice as a guide to improved farming methods (Williams, 1968), training of new, youth and women farmers as well as community reorganization.

The Japanese agriculture has thus far been successful and sustainable. This "suggest that farm decision-makers have either been using more and better information or becoming more knowledgeable" (Jones et al., 1987). The food shortage in the recent past has seen how important it is for nations to ensure 
sustainability of their agriculture sector. In fact, agricultural sustainability has been the focus of many developed nations as well as emerging economies. There have been a few interpretations of sustainable agriculture which could describe a state whereby: a) farm productivity is enhanced over the long-term, b) adverse impacts on the natural resource base and associated ecosystems are ameliorated, minimised or avoided, c) residues resulting from the use of chemicals in agriculture are minimised, d) net social benefit (in both monetary and non-monetary terms) from agriculture is maximised, and e) farming systems are sufficiently flexible to manage risks associated with the vagaries of climate and markets (Australian Standing Committee on Agriculture, 1997).

It would be interesting to understand how a developed country such as Japan manages its agriculture sector through the extension services, hence the study reported in this paper explored the roles and experience of the extension advisors in the context of knowledge creation and flow.

\section{Methods and procedures}

This study used questionnaire-based survey and interviews for data gathering. Eleven principal and senior extension and agricultural officers from different Prefectures and organizations and a consultant on the Japanese extension system were interviewed and 232 questionnaires were sent out to the extension advisors at the Headquarters and all of the 12 branches of the Ibaraki Prefecture Agricultural Center, Japan. Ibaraki is one of the 47 prefectures in Japan, with an area of $6,093 \mathrm{~km}^{2}$ situated in the northern part of the Kanto region in Honshu Island. It has close to 3 million population and in terms of productivity, in 2006, Ibaraki was ranked 4th most productive agricultural region with its production of vegetables, crops, flowers, fruits and livestocks (Ibaraki Prefectural Government, 2009).

One hundred and thirty-five completed questionnaires were returned, providing an overall response rate of $58.2 \%$. The breakdown of respondents according to branch is given in Table 1.

TABLE 1

Questionnaire Response Rate

\begin{tabular}{ccc}
\hline Branches of the Ibaraki Agricultural & $\mathrm{N}(135)$ & $\%$ \\
Center & & \\
\hline Bandou & 12 & 8.9 \\
Chikusei & 12 & 8.9 \\
Hitachiomiya & 13 & 9.6 \\
Hitachiota & 10 & 7.4 \\
Hokota & 12 & 8.9 \\
Inashiki & 12 & 8.9 \\
Kasama & 12 & 8.9 \\
Mito & 11 & 8.1 \\
Namegata & 9 & 6.7 \\
Tsuchiura & 12 & 8.9 \\
Tsukuba & 12 & 8.9 \\
Yuuki & 8 & 5.9 \\
\hline
\end{tabular}

The development of the questionnaire was based on the review of literature where a few open and close-ended questions were derived from themes from previous studies related to information management and agricultural extension services such as those conducted by Jones et al. (1987), Kaniki (1989), Rolling 
(1990), Majid et al. (2000), Middendorf (2007), and Fukuda (2008). Subsequently, interviews were conducted with several experts in the field of agricultural extension to ensure that the questionnaire items are relevant with the nature and characteristics of the extension advisory services. The survey instrument was reviewed by a number of senior extension advisors before it was distributed to the extension advisors.

Meanwhile, additional information was gathered through interview sessions with principal and senior agriculture officers from a national organization for agricultural extension, a national agricultural research institute, three Prefectural Agricultural Centers, and a retired expert and consultant on agricultural extension system. The purpose of these interviews was to seek further clarifications on their experiences on the overall development of the Japanese agricultural extension system in relation to inter-organizational linkages and co-operations, common practices and leadership of the extension services.

\section{Findings and discussion}

\subsection{Survey demographics}

Twenty-three (17.3\%) respondents were between 20 and 29 years old while the largest were in the age group of 30-39 years old $(30.8 \%), 32(24.1 \%)$ were between 40 and 49 years old, $34(25.6 \%)$ were between 50 and 59 years old, and only $3(2.3 \%)$ were 60 years old or more. Of the 134 respondents who provided feedback on their gender, $89(66.4 \%)$ were male and $45(33.6 \%)$ were female.

On their highest educational attainment, four (3.1\%) respondents held a PhD degree, 29 (22.5\%) had a Master's degree. The majority (79 or $61.2 \%$ ) of them had a Bachelor's degree. Only $1(0.8 \%)$ had only a college or high school education.

More than a third of the extension advisors who participated in this study had five years of working experience or less with the extension service, while $11(8.9 \%)$ had 36 or more years of experience. Table 2 provides detail breakdown about their experience.

TABLE 2

Experience of Respondents

\begin{tabular}{ccc}
\hline Experience (years) & $\mathrm{N}(124)$ & $\%$ \\
\hline Up to 5 & 46 & 37.1 \\
$6-10$ & 19 & 15.3 \\
$11-15$ & 15 & 12.1 \\
$16-20$ & 10 & 8.1 \\
$21-25$ & 9 & 7.3 \\
$26-30$ & 5 & 4.0 \\
$31-35$ & 9 & 7.3 \\
36 \& above & 11 & 8.9 \\
\hline
\end{tabular}

As extension advisors, respondents were assigned to 1 or more areas of specialty where $55(40.7 \%)$ respondents associated to vegetable farming, followed by rice cropping, 44 (32.6\%), upland cropping, 31 (23\%). Apart from farming and cropping, respondents also specialized in technology applications, $23(17 \%)$, human resource management, $22(16.3 \%)$ as shown in Table 3. 
TABLE 3

Area of Specialty of Respondents

\begin{tabular}{ccc}
\hline Area & $\mathrm{N}$ & $\%$ \\
\hline Vegetable farming & 55 & 40.7 \\
Rice cropping & 44 & 32.6 \\
Upland cropping & 31 & 23.0 \\
Technology applications & 23 & 17.0 \\
Human resource management & 22 & 16.3 \\
Business management & 20 & 14.8 \\
Fruit farming & 17 & 12.6 \\
Community development & 16 & 11.9 \\
Feed cropping & 13 & 9.6 \\
Flower farming & 11 & 8.1 \\
Dairy cow farming & 8 & 5.9 \\
Beef cattle farming & 7 & 5.2 \\
Pig farming & 6 & 4.4 \\
Chicken farming & 5 & 3.7 \\
\hline
\end{tabular}

\subsection{Personalized learning activities}

Respondents were asked to indicate on a scale of 1-5 (as noted below in Table 4) their preference of the channels of communication when interacting with farmers, the industry as well as with other organizations and related parties. It was discovered that extension advisors used several means to communicate with their clients in performing their advisory tasks and responsibilities. Table 4 provides the list of communication channels preferred and used by extension advisors and their mean score.

From the table, the channels which ware highly rated by the respondents were personal face-to-face meetings with farmers and other clients and visits to their farms and work places. The mean score for this preference was closest to 1 (most preferred). It is observed that the top 3 rated channels of communication (i.e. personal face-to-face meetings, visits; fixed line telephones and cell phones) would relate to the extension advisors' preferences for personal, on-the-spot and interactive communications with their clients.

TABLE 4

Preference of Different Types of Communication Channels

\begin{tabular}{clccc}
\hline \multirow{2}{*}{ Rating } & \multirow{2}{*}{ Types of Communication Channels } & $\mathrm{N}$ & $\begin{array}{c}\text { Mean } \\
\text { Score }\end{array}$ & $\begin{array}{c}\text { Standard } \\
\text { Deviation }\end{array}$ \\
\hline 1 & Personal face-to-face meetings, visits & 135 & 1.34 & 0.625 \\
2 & Office, residential fixed line telephones & 135 & 1.77 & 0.712 \\
3 & Cellphones, SMSes & 132 & 2.54 & 1.162 \\
4 & Handouts, flyers & 132 & 2.67 & 1.061 \\
5 & Workshops, seminars, classes & 131 & 3.18 & 1.094 \\
6 & Postal correspondences & 126 & 3.33 & 0.980 \\
7 & Emails & 128 & 4.13 & 0.908 \\
8 & Weblogs & 127 & 4.87 & 0.591 \\
\hline
\end{tabular}

Note: Scale: 1) Most preferred 2) Preferred 3) Neutral 4) Less preferred 5) Least preferred 
From the interviews it was possible to highlight that active learning happened during the interactions between extension advisors and farmers and between farmers where the more advanced farmers often provide assistance and guidance to other farmers. It was reported that farmers developed close collaborations between then through the formation of various local societies and groups. The extension services, on the other hand, constantly exchange ideas, experience and tacit knowledge with the farmers. The 'bottom-up' approach which is widely practiced in the Japanese agriculture permeates well with the extension's focus on personalized and repeated interactions. This approach apparently allows farmers to provide direct input to the development of the agriculture field. In addition, through this the extensions are able to gather firsthand information from farmers which are subsequently shared within the community and authorities for further actions.

This phenomenon (of personalization) is further evident by the preference of the extension advisors to meet with farmers at the latter's residence (mean score of 1.38 , where $1=$ most commonly at/on, $2=$ commonly at $/$ on, $3=$ neutral, $4=$ less commonly at/on, and $5=$ least commonly at/on), followed by farmers' farmyard (mean $=1.94)$. Table 5 provides the list of meeting places rated by extension advisors.

TABLE 5

Preference of Places of Meeting With Farmers

\begin{tabular}{clccc}
\hline \multirow{2}{*}{ Rating } & \multicolumn{1}{c}{ Places of Meeting } & N & $\begin{array}{c}\text { Mean } \\
\text { Score }\end{array}$ & $\begin{array}{c}\text { Standard } \\
\text { Deviation }\end{array}$ \\
\hline 1 & Farmers' residence & 134 & 1.38 & 0.691 \\
2 & Farmers' farmyard & 132 & 1.94 & 0.955 \\
3 & Respondents' office & 132 & 2.64 & 0.967 \\
4 & Workshops/classes/meetings & 131 & 2.69 & 0.894 \\
5 & Local agricultural cooperatives & 130 & 2.92 & 1.061 \\
6 & Experimental plots/sites & 129 & 3.19 & 1.146 \\
\hline
\end{tabular}

It would be interesting to highlight that the interactions between the players in agriculture provide a platform for formal and informal exchanges of ideas and experience, which gradually formed into what is called communities of practice (Wenger, 1998) where individuals through active social participation contribute to the practices of and learning in their communities and/or organizations. Wenger believes that 'learning is an issue of sustaining the interconnected communities of practice through which an organization knows what it knows and thus becomes effective and valuable as an organization' (p. 8). Sharing of one's experience is an integral part of a community where the alignment of individuals towards common goals may facilitate change within the community (Kahan, 2004).

Therefore, we can conclude that in the context of the agricultural extension, social interactions and participations between advisors and farmers lead to the creation and sharing of new knowledge which would contribute to the enhancement and sustainability of the agriculture sector. In this case, the extension advisors act as intermediaries and key players in the community.

\subsection{Need-based and personal sources of information}

Respondents were asked to indicate from 17 items on where they acquire 
and seek the information required to perform their advisory and administrative tasks. Table 6 shows the list of advisory information and the sources used by the extension advisors in performing their advisory tasks. Of the 19 types of advisory information, 12 were acquired from their Prefectural Agricultural Center, 2 each from the Ministry of Agriculture, Forestry and Fisheries (MAFF); mass media; and customers and farmers; and 1 from their superiors, colleagues and subordinates.

It is obvious from Table 6 that the Prefectural Agricultural Center caters for most of the advisors' needs for information which spans from R\&D findings, new technology, technical aspects of agriculture to managerial issues. The MAFF meanwhile was referred to for governmental incentives and policies as well as legal and regulatory information. Information pertaining to the needs of specific farmer groups and community development were acquired from their clients themselves. The mass media were relied upon for news on global and local affairs and finally, for information on credit system, they referred to their superiors, colleagues and subordinates.

We can conclude that the Prefectural Agricultural Center possesses a repository of tacit and explicit knowledge which could be easily accessed and used by the extension advisors in performing their advisory tasks. The availability of such facilities is an integral part which would enhance knowledge sharing within the organization.

TABLE 6

Sources of Information for Advisory Purposes

\begin{tabular}{|c|c|c|c|}
\hline Advisory Information & Source & $\mathrm{N}$ & $\%$ \\
\hline New research \& experiment findings & Prefectural Agricultural Center & 74 & 55.6 \\
\hline New technology development & Prefectural Agricultural Center & 70 & 52.6 \\
\hline Government incentives \& policies & $\begin{array}{c}\text { Min of Agriculture, Forestry \& } \\
\text { Fisheries }\end{array}$ & 61 & 46.2 \\
\hline Legal and regulatory information & $\begin{array}{c}\text { Min of Agriculture, Forestry \& } \\
\text { Fisheries }\end{array}$ & 67 & 51.1 \\
\hline Farm management methods & Prefectural Agricultural Center & 38 & 29.0 \\
\hline Technical specifications & Prefectural Agricultural Center & 42 & 33.6 \\
\hline Soil improvement & Prefectural Agricultural Center & 57 & 44.2 \\
\hline Plant/animal breeds & Prefectural Agricultural Center & 36 & 27.9 \\
\hline Pest \& disease control & Prefectural Agricultural Center & 63 & 49.2 \\
\hline Natural disaster protection & Prefectural Agricultural Center & 57 & 45.6 \\
\hline Water \& irrigation systems & Prefectural Agricultural Center & 37 & 30.8 \\
\hline $\begin{array}{l}\text { Farmer groups' needs \& } \\
\text { requirements (new, young \& } \\
\text { women farmers) }\end{array}$ & Customers, farmers & 59 & 46.5 \\
\hline Community reorganization & Customers, farmers & 29 & 22.8 \\
\hline Food safety & Prefectural Agricultural Center & 28 & 21.9 \\
\hline Environmental issues & Prefectural Agricultural Center & 34 & 26.6 \\
\hline $\begin{array}{l}\text { Local market information (including } \\
\text { prices \& consumer demands) }\end{array}$ & Prefectural Agricultural Center & 28 & 22.0 \\
\hline Credit system & $\begin{array}{l}\text { Superiors, colleagues, } \\
\text { subordinates }\end{array}$ & 37 & 28.9 \\
\hline Current global affairs & Mass media & 61 & 47.3 \\
\hline Current local affairs & Mass media & 53 & 41.1 \\
\hline
\end{tabular}

Similarly, the respondents were given a list of 10 types of administrative information to indicate the sources of information in performing them as listed in Table 7. It shows that 6 types of administrative information were acquired from their superiors, colleagues and subordinates. This is followed by 2 each from the Prefectural Agricultural Center and their customers and farmers. 
In relation to the high preference for sources of information from the Prefectural Agricultural Center, it could be argued that the concepts of communities of practice and organizational learning with individual active participation and sharing of experience are indeed well observed and activated at this Prefectural Agricultural Center. It is evident that human expertise and experience are the main source of information and shared within the organization as the main ingredients for decision-makings, aligned toward the achievement of organizational goals.

TABLE 7 Sources of Information for Administration Purposes

\begin{tabular}{|c|c|c|c|}
\hline Administrative Information & Source & $\mathrm{N}$ & $\%$ \\
\hline Making predictions and forecasting & Superiors, colleagues, subordinates & 32 & 26.0 \\
\hline Doing research and experiments & Prefectural Agricultural Center & 68 & 55.7 \\
\hline $\begin{array}{l}\text { Providing feedback on community } \\
\text { issues to research institutions }\end{array}$ & Customers, farmers & 42 & 33.6 \\
\hline Preparing presentations & Superiors, colleagues, subordinates & 33 & 27.0 \\
\hline Preparing reports for farmers & Superiors, colleagues, subordinates & 36 & 28.8 \\
\hline For personal and private use & Customers, farmers & 22 & 17.5 \\
\hline On-the-job training & Superiors, colleagues, subordinates & 43 & 36.4 \\
\hline Preparing departmental reports & Prefectural Agricultural Center & 37 & 31.1 \\
\hline Preparing institutional strategic plans & Superiors, colleagues, subordinates & 42 & 35.0 \\
\hline Responding to emergency cases & Superiors, colleagues, subordinates & 45 & 37.2 \\
\hline
\end{tabular}

\section{Conclusions}

This study highlights an integral factor that contributes to the success of an organization that is the ability to generate and share knowledge among members of the organization. Results showed that the agricultural extension system actively promotes and facilitates the sharing of ideas and experiences between extension advisors and farmers as well as other stakeholders.

Farmers have learned that agriculture is a risky business, hence they need to make accurate decisions based on real life experience and specific knowledge to ensure that they could get the appropriate return on investment and to minimise losses. They need constant, accurate and timely advice from the extension services and other advanced farmers. The agricultural extension organizations naturally provide the place or the Japanese concept of 'ba' (Nonaka \& Konno, 1998), which means 'a shared space that serves as a foundation for knowledge creation' (p. 40) for the promotion of active interactions, consultations and exchanges between extension and farmers.

An example of the initiative that creates the ba is the on-the-job training (OJT) for farmers through on-site and hands-on sessions, and for extension advisors which is widely practised in most Japanese organizations. It is worth noting that Japanese organizations adapted the OJT concept into their work culture which allows the sharing and flow of implicit knowledge among members. The open office concept where workers are placed closely together in an open office space helps to further enhance the OJT practices, thus allowing for ideas and experience to naturally flow, underpinned by a situation referred to by Nonaka and Konno as 'entrainment' (synchronizing behaviour), and eventually got aligned towards the common culture and goals of the organization.

The findings of this study have provided some insights as to the ways in which knowledge is created and shared within an organization and are expected 
to serve as an initial framework for organizational leaders to create opportunities and space for such activities to be carried out. Future research may be conducted to find out the state of knowledge creation and sharing in the other Prefectures and in other organizations in general.

\section{Acknowledgements}

The authors acknowledge with gratitude support from Universiti Teknologi MARA, Malaysia; Research Center for Knowledge Communities, the University of Tsukuba, Japan; and collaboration of the Japan Agricultural Development and Extension Association (JADEA); Japan National Agricultural Research Center (NARC); Agricultural Center of Ibaraki and Toyama Prefectures and Hokkaido; Tochigi; Dr. Yasuki Fujita; Mr. Asahi Kiyokawa; the respondents and consultants.

\section{References}

Australia. Standing Committee on Agriculture (1997). Sustainability indicators for agriculture: introductory guide for regional/national indicators and on-farm indicators.

Fujita, Y. (n.d.) Japan's extension system for improvement of agriculture and rural life. Unpublished paper.

Fukuda, K. (2008). Study of problems and improvement measures of information activities used with information technology in agricultural extension. Tokyo: Japan Agricultural Development and Extension Association.

Ibaraki Prefectural Government (2009). Data on Ibaraki. Mito: Ibaraki Prefectural Government. Available at http://www.pref.ibaraki.jp/bukyoku/seikan/kokuko/en/data/index.htm

Japan Agricultural Development and Extension Association (2005). Nougyo fukyu jiten $=$ Agricultural extension services overview \& perspectives. Tokyo Maruikoubunsha.

Jones, G. E.; Rolls, M. J. and Tranter, R. B. (1987). Information management in agriculture : British Library R\&D report 5931. Reading, England : Agricultural Extension and Rural Development Centre.

Kahan, S. (2004). Etienne Wenger on communities of practice: engagement, identity and innovation. The Journal of Association Leadership, March 2004.

Kaniki, A. M. (1989). Agricultural information needs in Zambia: a study of a two-way information flow. Unpublished doctoral thesis. University of Pittsburgh.

Majid, S.; Anwar, M. A. and Eisenschitz, T. S. (2000). Information needs and information seeking behavior of agricultural scientists in Malaysia. Library \& Information Science Research, 22(2), 145-163.

Middendorf, G. (2007). Challenges and information needs of organic growers and retailers. Journal of Extension, 45(4). Available at: http://www.joe.org/joe/2007august/a 7.shtml

Nonaka, I. and Konno, N. (1998). The concept of 'ba': building a foundation for knowledge creation. California Management Review, 40: 40-54.

Roling, N. (1990). The agricultural research-technology transfer interface: a knowledge systems perspective. In David Kaimowitz (Ed.). Making the link: agricultural research and technology transfer in developing countries. London: Westview.

Wenger, E. (1998). Communities of practice: meaning, and identity. London: Cambridge University Press.

Williams, D. (1968). Agricultural extension: farm extension services in Australia, Britain and the United States of America. London: Cambridge University Press. 
